\title{
Truncated Cosmopolitanisms: Post-apartheid Literary Identities in Ivan Vladislavić's The Exploded View
}

\section{Introduction}

South African writer Ivan Vladislavićs's The Exploded View tells the stories of four seemingly unconnected individuals who inhabit the shared imaginative space of Johannesburg. ${ }^{65}$ It is through their maneuvers of belonging and self-affirmation that Vladislavić further instantiates the ideas of writing the postcolonial metropolis, and in doing so, shows again what I contend his oeuvre to be almost entirely constitutive of-the paradox of the urban condition in a specific South African city. While one can potentially deconstruct any text, The Exploded View lends itself particularly to deconstructive readings, as evidenced (to begin with) in the structure of the text, which, from a cursory reading, appears to be comprised of four totally disparate narratives, but on closer examination is revealed to be a narration of closely connected spaces, rendered through multiple perspectives. These perspectives offer glimpses into the transient social and material spaces of the city in which characters are located and imagined events take place. In this way, Vladislavić draws clear links between the actions of individuals and the material realities that inform and affect their actions and decisions.

With respect to the last two strands of the quadruple-pronged narrative of The Exploded View, this chapter is focused on making similar connections in order to better contextualise the writer's consideration of the characters' (multiple) identities within specific and shifting historical milieu. The first part of this chapter is theoretically framed by what Shane Graham has described as Vladislavić's use of the "metaphor of the exploded view as a representational strategy." By, in effect, doubling this metaphor on itself, I will use it as a tool of analysis to examine the attempts of Simeon Majara (the central character in "Curiouser") at re-signification and re-presentation of the Rwandan holocaust, on one hand, and common curio pieces, on the other. Veronique Tadjo reminds us in The Shadow of Imana: Travels in the Heart of Rwanda of the difficulties of finding the appropriate idiom, as well as the role of language and memory in representing trauma on the personal scale and at the level of genocide.

65 Unless stated otherwise, all parenthetical citations invoking Vladislavić refer to The Exploded View. 
The second half of the chapter, focusing on "Memory and the "Architecture of Hysteria" " will, through a critical reading of "Crocodile Lodge," discuss the nervous energy and backward glances that accompany Gordon Duffy's forays into an emergent discursive terrain and urban space that paradoxically engenders hope and despair in equal measure.

This chapter is therefore entitled "Truncated Cosmopolitanisms" in reference to these shadow identities that appear on and fleet across the stage of a cityscape that is itself undergoing constant change in its physical infrastructure, as well as its socio-political dynamics. Taken together as a composite whole, the characters give the impression of being the embodiment of a post-apartheid identity that typifies the philosophical and social integration at the heart of the Rainbow Nation. ${ }^{66}$ The narratives and lives of the characters are linked in subtle, implicit, and not too easily discernible ways, an aspect that is reflective of the often-unintended interactions, anonymous path-crossings, and accidental entanglements that characterize the postcolonial city.

\section{Locating Majara as an "Aesthetic Bohemian"}

Simeon Majara, the main character of "Curiouser," is an established black multimedia artist who resides in suburban Johannesburg. He represents something of a departure from the more familiar Vladislavić characters, who are, generally-speaking, white males battling to assert agency in an alienating and disillusioning city. Majara or "S. Majara," as he often somewhat egotistically refers to himself, instantiates a different kind of postcolonial city subjectivity and identity. Along with Boniface Khumalo in the short story "Propaganda by Monuments," he is one of only two major black characters in the now extensive oeuvre of Vladislavić. Majara represents an enigmatic cosmopolitan outlook in ways that his predecessor, Khumalo, does not. The latter is conceived and portrayed in the manner of a man who is conscious of a particular material upbringing (mainly because of his race) and continues to engage with the post-apartheid city largely from that perspective. Khumalo is not racist, nor does he continue to fight a racial struggle, but rather, he utilizes the cultural capital and tools at his disposal, mainly as result of his race and upbringing, to fashion new sets of identities for himself in the emerging metropolis. His entrepreneurial activity is linked

66 The term is first attributed to the retired Anglican Archbishop of Cape Town and prominent antiapartheid activist, Desmond Tutu, and was also used by Nelson Mandela in his 1994 Inauguration Speech-“Glory and Hope.” 
to and steeped in the broader struggles for social and political justice in South Africa, and he maintains a consciousness that is grounded in his township background. ${ }^{67}$

\section{Illusory Authenticity}

For his part, Majara does not overtly represent himself as black, that is to say, he does not display any supposedly black traits or signs of blackness. He appears not to be culturally embedded, in ways not dissimilar to the ones that Graham critically describes as being typical of a depoliticized "aesthetic bohemian" (Graham 49; Nuttall 741). In the appellation "S. Majara"-mentally evoked with the requisite flourish-the name comes to define individual identity more than is the case with any of Vladislavić's other fictional characters. Often, he introduces himself as "S. Majara," as if he is signing off his latest artistic masterpiece, rather than engaging in a mundane conversation. It is an instance of the self-indulgent branding that has become increasingly visible with the global growth of celebrity culture, an extreme example of which is how the name of a person replaces any artistic or other merit that they may have. This also shows how the postcolonial city is linked to global networks and trends.

The main question to be considered, in this light, is whether indeed and to what extent Majara represents a new postcolonial, cosmopolitan subjectivity, more so when one reflects on the fact that most of his acquaintances, girlfriends included, are white. These new subjectivities and ways of being are shown not only in the way that Majara, in the guise of the avant-garde artist, is represented, but also in the strategies that he adopts in constructing and positioning his own identity. His celebrity and reputation are built more on his ability to shock, as opposed to the aesthetic value of his work. It is important to interrogate what Majara's art suggests, broadly, about representation ${ }^{68}$ and how this self-reflexively sheds light on him as a figure occupying a specific locus in the continuum of the emergent postcolonial city.

To celebrate his latest show ${ }^{69}$-Curiouser-which has just come down at the Pollak Gallery, Majara holds what is known in the parlance of the day as "a closing”-

67 This is not to suggest that Khumalo is inward-looking in a developmentally fatal way but that he acts locally, while attempting to think globally. His marketing of his township tavern as the V. I. Lenin Grill and Bar shows just such global "awareness.” For instance, Khumalo's letter to the authorities in Russia is couched in Marxist terms that identify it with both the Soviet communist party and the struggling masses of South Africa.

68 Leon de Kock has suggested that in The Exploded View Vladislavić "exposes the artifice of artmaking" (14-15).

69 The staple of the show are animal figures or curios that are taken apart and then put together again in new ways, sometimes with parts of one animal incorporated into a biologically different one, or even parts of the same animal re-assembled in new configurations and patterns. It is literal deconstruction. 
as opposed to an opening. Curiouser, his exhibition of everyday tourist curios that have been disassembled or otherwise disfigured, reinterpreted, and reconstructed as serious art, has received critical success and blatantly "exploited the art world's avid pursuit of novelty" (Marais 30). The title of the display-an overt play on curios/ curious/curio-user-shows how quickly and easily, with the aid of often very subtle adjustments, the signification of signs and artefacts can be changed. A case in point is that when he is making the mask-lanterns by drilling holes in the temples of each mask, through which to tie the string that holds them together, Simeon notices how the mere act of wielding the drill changes the peculiar meanings evoked by one of the masks: "As he pressed the bit against the forehead, he studied the expression. You could imagine that it was gritting its teeth-but that was just the effect of the drill. If you took the bit out of the picture, the grimace turned to a grin" (Vladislavić 102).

In the quote above, the expression on the masks can be read as a grimace or grin depending on whether the artist is holding the drill bit or not, and illustrating yet again the fluidity of signification. The physical expression on each respective mask remains the same; what changes is what each signifies changes depending on the context in which it is viewed. For the Bra Zama Eatery project, he had acquired six crates of masks from a Malawian vendor who imported curios, and hence had more than he needed. The artistic value of the masks is diminished by the fact of their mass production, ${ }^{70}$ and Majara seeks to restore some of the elements of unique creativity (that define the difference between original art and reproduced crafts) by putting them together in new and unexpected and unpredictable ways.

The opportunity to be involved with the themed design of the interior decor of the eatery comes through a third party, a white woman who was an acquaintance of Simeon and occasionally framed his printed artwork. She had, however, decided to share the commission with him because she thought that "he knew more about authentic African style than she did-he was black, after all, never mind the privateschool accent" (Vladislavić 105). This statement, patronising as it is, puts into question several key aspects of Simeon's identity. The first is the definition or evaluation of Africanness, especially where its supposed qualities are defined as being somehow an inherent part of the make-up of the individual. There is a suggestion that blackness or being African is more a biological and less a socio-cultural fact since his friend assumes that because he is black or African, he is therefore naturally attuned to what is "authentically" African. Resorting to stereotype, she quickly dismisses any impact socialization (through attending private school) might have on his sensibilities. The terms African and black(ness) are not unproblematic because they are not universal signifiers that are equally applicable to all individuals who are racially defined as

70 An ironic process of commodifying art which, though intended to ensure economic survival for the artist, often has the opposite effect of cheapening the artefacts to the extent of wiping out any financial benefit. 
such. I mentioned a little earlier the perceptions of Majara as being acontextual in his demeanor, at least in the sense that his artistic and cultural inspiration is not limited to any recognizable font that is part of his personal and national histories. The other consideration that flows from this construction of him as the disembedded subject is that of authenticity as defined by his unnamed friend. The latter starts from the assumption that the design of what is an "authentic African style" flows naturally from the fact of Majara being black.

\section{Representing the Unspeakable}

The second ${ }^{71}$ in a series of exhibitions on the theme of genocide, Majara's show on the Bosnian massacre at Ahmici creates interest because "people were intrigued that a black artist should be dealing with Bosnia" (Vladislavic 104). Again, the question is the extent to which a black artist can authentically represent a historical event that occurred somewhere in the Balkans, a place from which it is assumed the artist is culturally removed. Post-exhibition reviews of the display highlight how the origin of the artist had no effect on the impact of the artwork as "no one who saw it remained unmoved" as "[i]t made you painfully aware that you were corporal and mortal" (104). This is an illustration of the power of all forms of artistic expression to at times transcend the normative strictures of culture and history. The follow-up project, which Majara christens Genocide III, focuses on the scene of the Nyanza massacre, one of the many heinous incidents of mass slaughter that occurred during the time of the 1994 genocide. With respect to the two previous exhibitions, there is no mention that he actually travelled to the sites of the genocide, but for the Nyanza Shrouds-as it comes to be known among critics and admirers-Simeon Majara does travel to Nyanza as part of a motley tour group which includes journalists, a cultural researcher, a socio-religious activist involved in a church program to assist orphans, and even some actual tourists. As a theme, transnational travel is quite unusual in Vladislavić's writing as his characters generally tend to perambulate within the same urban locale. In this respect, Simeon Majara represents something of a departure from type. Among the traveling group is Henk from Groningen (Netherlands), a selfstyled “cross-cultural adventurer" for whom genocide held a special appeal: "He had done the major concentration camps in his own backyard (Auschwitz, he said, was still the must see), the Tuol Sleng Genocide Museum in Phnom Penh, and a five-day drive along the Trail of Tears. This was his first African visit, but South Africa was next on the list” (Vladislavić 105). Henk's involvement in the group and his revelation

71 The first in the series was on the holocaust of World War II and used ashes and soot as its primary medium, thus evoking the gas chambers. 
that genocide sites are effectively a personal obsession raises questions as to what constitutes the authentically 'tourist' experience and whether visits to such sites can be considered edifying when viewed from such a perspective. ${ }^{72}$

The principles involved in Henk's visits are similar to those used in the artist's consideration of which subject (matter) to represent and how to do so in a manner that is original yet authentic, thus emphasising the question of representation. By styling himself as an adventurer who visits all the sites of the major genocides of modern history, Henk comes across as little more than a callous and sadistic voyeur who seeks to retrospectively witness scenes of extreme mass trauma. In contrast, Majara could not reveal to his fellow traveller his true vocation as an artist: "Simeon could not bring himself to say he was an artist. The idea made him queasy. It suggested an intolerable common purpose with his fellow traveller, whose bony knee was rubbing against his own. He said he was a journalist and patted his bag" (105). What makes him "queasy" is fear of being perceived as a practitioner of art for art's sake, of being a purveyor of artistic shock that has little or no value beyond the defined universe of the specific artwork itself. This is not to suggest that his audience is not also involved or invested in this "universe," but rather, he wishes his art to be perceived as being more profound than its mere shock value. Hence he resorts to what he imagines to be a more acceptable explanation of his presence in Nyanza-as a journalist.

Discussing the writing of Travels in the Shadow of Imana with Stephen Gray, Veronique Tadjo asserts that it was based on the premise that it was an attempt to write about the Rwandan genocide purely from the standpoint of a writer, as opposed to journalist or historian (Gray 146). There are always questions regarding the effects of stylistic mode on the authenticity and realism of representation, hence Majara's "resorting" to the guise of a journalist while Tadjo and her colleagues are "instructed" to write as writers. In a way, both Majara's fake journalism and Tadjo's writing as a writer are different examples of attempts to represent "reality"-a state in which the act of representation is beyond aesthetic and symbolic reproach. However, the purity of the gaze implied above is not ultimately possible because reality will always, as suggested by Derrida, be mediated through language (DeFazio 57).

In a destroyed clinic in Nyanza, Majara discovers old plaster bandages that had remained untouched since before the time of the massacre, while taking still pictures and videos of the vacant rooms. The plaster on the bandages has dried into fine dust and becomes the motif for Genocide III (his Holocaust exhibition was themed on ash and soot, and the Bosnian one on bone). He furtively deposits the 20 rolls of bandage in his camera bag and returns to Johannesburg with his "contraband" to be used later. Part of the exhibition has twenty billowing shrouds, into each of which one of the bandages had been woven. They are hung behind a giant screen (showing video footage

72 There is a broader field of the study of the politics of traversal, which is epitomized, for instance, in John Urry's The Tourist Gaze (1990). 
shot in Nyanza) as the pièce de résistance. Imprinted onto the shrouds are images modelled on the artist's own body, such as "a crying mouth, a twisted arm, a hand raised to ward off a blow" (Vladislavić 112). This last aspect naturally draws protestations about his vanity, criticisms which he fends off by rationalizing that his actions were actually "a mark of humility" in that he took himself "as the template" and "immerse[d] himself in the image of the other like an armature in a sculpture" (115).

By putting his likeness into the images that are supposedly commemorating lives that were so brutally lost, Majara raises issues and contestations around the question of whether he is merely indulging his ego and sense of self, and whether indeed the exhibition is less a memorial to the genocide than a celebration of the artist, the individual. Seen this way, his art is about individuating and stylizing himself as S. Majara, rather than about the Nyanza massacre. Such a position, on his part, is contrary to the ethos of Ubuntu; ${ }^{73}$ it is against the spirit of an African humanism that tends to foreground communal and social good ahead of individual attainment. Majara displays, in this instance, some characteristics that illustrate how he possesses more than just a private-school accent; rather, he has internalized more fundamentally Eurocentric or Western conceptions of the self. He is, effectively, a fore-runner to the now pervasive pseudo-celebrity and self-writing culture that has emerged with the growth of the internet and social media. In this respect, he has the appearance of the "coconut,"74 a much-ridiculed figure of the post-apartheid era. The very thing that he discerns and abhors in Henk-the idea of an adventurer seeking out sites of genocide as a source of thrills-is what Majara becomes with his utilization of the exhibit as a means of selfaffirmation or validation.

By seeming to self-promote at the expense of the victims, Majara also initiates another tangential consideration of the role of art and other representational strategies. Writing on the tenth anniversary commemoration of the genocide by Rwandan President Paul Kagame's government-held under the thematic banner of "Never Again,” echoing a post-World War II mantra-Nicholas Mirzoeff is of the view that the remembrance of the genocide in Rwanda has in this way "resist[ed] representation and retreated into invisibility" (57). The first part of the excerpt above speaks to the difficulty of representation. It is my contention that, even taking into account the differences in scale between the commemoration by the Rwandan nation and Majara's gallery showpiece, which uses his own body as proxy, ${ }^{75}$ the artist in similar ways

73 A basic tenet of Ubuntu is "umuntu umuntu ngabantu," which can be loosely translated as "a person is a person because of other people." This philosophy privileges the primacy of the group over individual considerations.

74 "Coconut" refers to someone who is said to be black on the outside and white on the inside. The image evokes some of the social and cultural contradictions that emerge in the postcolonial city.

75 In the pamphlets for the show, Majara does not intimate the source of the bandages that are sewn into the shrouds and also edits footage out of the video that shows the moment of their discovery, thus protecting and enhancing his own reputation as a creative genius. 
erases the memory of the genocide. Mirzoeff's analysis is relevant here because when Kagame frames the 1994 killings in the same rhetoric as the Holocaust of World War II, the Rwandese events are not defined in their own terms, which accounts for the resistance to representation and its (the Rwanda genocide) sliding into indistinctness. It is for this reason that Simeon Majara's show becomes just that, a show about the artist and less about the ethnic cleansing.

The multiple textures of the exhibition allude to the multiple voices through which any story can be told and thus recalls the metaphor of the exploded view. Majara finds that neither the bandages, nor the still pictures, nor the shrouds can encapsulate and represent the specific meanings that he seeks to disseminate about the genocide. This notion of a multiplicity of perspectives-accidentally also present in the writing of Tadjo about the genocide-arises from the many voices that seek to tell, and make sense of, the story of ethnic cleansing in Rwanda, not least that of the artist and the writer. It is at the heart of the difficulty of and resistance to representation. Tadjo's journey through Rwanda begins even before she arrives in the country when, in Durban, she has a chance encounter with a Rwandan refugee who is now eking out a living by guarding parked cars. He is described as having "fled to the very edge of the sea" (Tadjo 5), and this meeting is marked by a quite instructive irony of circumstance. On the one hand, there is the survivor-victim of the genocide who seems to only have been stopped by the sea in his desperate flight from his homeland; had there been no sea, it is implied, he would still be running. Yet, on the other hand the author is headed in the opposite direction and hoping to make sense out of the events in Rwanda. The challenge for Tadjo as a writer is to verbalize this man's peculiar trauma in a manner that is both accurate and not demeaning of his dignity. But as she accedes, “The truth is revealed in people's eyes. Words have so little value. ... See what is inside" (5). The guide for Majara's party in Nyanza is also a survivor of that slaughter; he survived only by lying among the corpses and pretending to be dead. In fact, he had "become" death as the trauma of hiding himself amongst the dead and dying had meant that "[d]eath had rubbed off on him, it was there in his skin" (Vladislavić 110). As with Tadjo's car-guarding refugee who has witnessed horrors that have induced in his eyes an opaque and lifeless quality, the trauma of a living death is something not quite definable or tangible. It remains just beyond comprehension and depiction. The connection between the Rwandan genocide and living in the postcolonial city is implicit in the acts of one individual, Majara, who utilizes the repertoires of representing the genocide to also articulate his own sense of self and agency. He marks himself as different from all the other residents of Johannesburg, artistic or otherwise, through his art. 


\section{Postcolonial Identity: A Paradox}

Beyond the art gallery, "Curiouser" as a narrative thread continues to instantiate questions on identity and how it shifts through and with discourse. This is a reiteration, in slightly different paradigms, of the unsettling doubts that assail most of Vladislavić's (mainly white) characters in terms of whether or not they have any sense of belonging to and identify with the social, physical, and psychic space of the postcolonial city. In the course of the evening gathering to celebrate Curiouser (the art show), debate turns to the source of the masks among those assembled (all arty types and predominantly white with an insignificant sprinkling of black faces like Bheki). This innocuous enquiry soon ushers in a broader discussion on the meaning of being black and African. Simeon Majara narrates how he came upon the cheap masks through Roger, a Malawian curio vendor at Bruma in Johannesburg. But this raises accusations of Majara's complicity in the disposal of stolen goods: ${ }^{76}$

"You are dealing in stolen property, you shit."

"I'm hardly dealing. Mind you, it's quite a nice twist. If you consider how much African art has been swiped by the real dealers, the wheeler-dealers."

"I'm sorry, you'll have to explain. How is this different?"

"I'm an African for one thing."

"You mean you're black."

"That's not what I said."

"This Roger," James butted in, "the seller, the fence-he was African too."77 (Vladislavić 131)

This is the only time in the narrative that Majara overtly claims African identity. At all other times in the story, he is happy to individuate himself as S. Majara-the

76 A related point is raised later in the evening by Amy, concerning the fact that Simeon makes more money with the reconstructed masks and curios than the original artists. He replies that, "the curio is in one system and the art work in another. If you move an object from one system into another, by the sweat of your brow, you change its purpose and therefore its value" (Vladislavić 146). Still, Amy gets the last word, asking him to imagine how "the people who made these masks must live" and compare that "with the way you live here" (146). For her "[i]t's just a question of awareness, of being conscious and staying conscious of how things are, even if you can't change them. Especially then" (147). Amy's position, even if suspiciously liberal in outlook, shows a greater mindfulness of the social and historical complexities involved in the production of Simeon Majara's art.

77 After they have the food, Simeon reveals that he has been invited to show some of his work in Sweden, whereupon Leon, with whom there are suggestions in the text that he seems to be waging a low-intensity civil war of attrition, cynically suggests that the invitation had been extended "because you're an African" and not, as Simeon had attempted to pre-emptively say: "She invited me because I'm black?" Majara's response here is markedly different from his earlier self-definition as "African." The main question is whether he is using the terms "African" and "black" interchangeably now, where before he had been so assertive in stating that he is African as opposed to being just black. This again illustrates the notion of identity as a fluid terrain and how, in the context of the postcolonial city, the sense of self constantly faces disruption and change. 
artist-but in the excerpt above he identifies with the collective concept of an African identity. His reasons have less to do with any sudden realization that he is indeed African-before everything else he might claim to be-but, rather, they are a means of deflecting criticism that he has an exploitative relationship with the makers of the curios that he deconstructs into new art-works, and in that respect is no different from the figure of the colonial European. In the exchange quoted above there is an intriguing distinction that Majara makes between being black and being African, a distinction that also illustrates the difference in perspective that different characters have in their perceptions of identity. In the incident involving Henk in Nyanza, Rwanda, the construction of such an identity is much more implied (in the disavowal of the "intolerable common purpose" with Henk, who is the archetypal European "adventurer") than it is directly asserted. On the other hand, in the context of South African racial discourse, being black often carries with it the connoted baggage of victimhood and entitlement. By displacing the signifier "black," Majara can therefore pre-empt some of the potentially patronizing criticism that would be directed against him because of the perception that he behaves the way he does because of his blackness.

It is significant that Majara positions himself in the discourse by privileging the aspect of his Africanness over that of his race as a black man. There seems to be no debate amongst the participants in the conversation as to what differentiates the two as diverse expressions of identity, and it is implied that all understand the distinction. There are two possible explanations for the paradox that is Majara, who seemingly is simultaneously able to occupy space outside and within his own history. The first is that he is a purveyor of the new African cosmopolitanism that was espoused by South Africa's second post-apartheid president, Thabo Mbeki, in his "I am an African" speech to parliament on May 8, 1996. In this speech, made when he was still the deputy president and acclaimed by some as one of the greatest speeches ever made by an African, Mbeki (1996) speaks of an African identity that is not purely atavistic and the subject of a demeaning anthropological discourse but, rather, an African humanity that is forged in the furnace of the diverse histories of all the peoples who have called, chosen to call, or been forced to call Africa home.

The second possibility is that Majara resorts to an African identity as a defensive strategy in the face of accusations that he is plundering African art in a manner not dissimilar to the colonial and latter-day European "wheeler-dealers." By inference, if he is African, he cannot then be said to be engaging in such exploitative exchanges because, being African, he is incapable of the same. In asserting this Pan-African identity, which can also be termed an Afropolitan sensibility, Majara attempts to signal that, as a consequence, he can therefore not be deemed to be an exploiter of African art and artists. In this consideration, the African identity then becomes a convenient cloak that is worn and discarded as the situation requires. Even more importantly, this shows how some characters in the postcolonial city that is the subject of Vladislavić's writing are able to assume particular identities as they appropriate space. Identity can therefore not be seen as fixed or complete because individuals can 
assume particular identities, depending on the socio-economic space in which they find themselves or to which they aspire.

The short time that elapses between his moment of assertive certainty about Roger's identity and the rising doubts about whether in fact the vendor was Malawian clearly illustrates the fluidity in the perceptions and constructions of identity: "What did a Malawian look like? There had been a Malawian kid at school with him, a couple of classes below, the son of a diplomat-'from a diplomatic family,' his mother said. Was Freddy Chavula typical? He could hardly remember now what he looked like. The only other Malawian he could picture was Hastings Banda" (Vladislavić 133). ${ }^{78}$ Here Majara seems to have retreated from the cosmopolitan Pan-Africanist posture because he is trying to differentiate between people on the basis of the flimsy category of nationality, as portrayed in the question: What did a Malawian look like? Expressed in his thoughts is the idea of identity being an abstract concept, as he battles to define anything that is tangibly Malawian about Roger or Freddy his schoolmate, or even the late former Malawian dictator-Hastings Banda.

In reading the "Curiouser" segment of The Exploded View, my intention has been to show how in the act of self-styling, or otherwise defining notions of the self in the postcolonial cityscape of Johannesburg, Simeon Majara lays bare some of the sociohistorical pitfalls attendant on the exercise. These have to do with the premises on which such constructions of identity are dependent and also the fact that individuals in interaction with others have their identities construed and constructed by the people with whom they are in contact. Individuals shape each other's identities in reciprocal fashion.

In the course of stylizing himself through his art, other people are also able to construct their own notions of his identity through their responses to his art. I have used the difficulty of finding a universally resonant idiom that adequately reflects, for instance, the Rwandan genocide-by looking at Majara's art and glancing comparatively at the difficulties enunciated by Tadjo in her efforts to render in written words the trauma of the genocide-to show the difficulty of selecting, in general terms, a metaphor of representation. Through the parallel discussions of the almost imperceptible dichotomies between being African and being black, I illustrated how the terms are not mutually exclusive, as highlighted in the instance in which Majara is seemingly confused in referring to himself as black whereas before he had been forthright in declaring that he is African.

78 Hastings Banda led Malawi to independence from British colonial rule on July 4, 1964, before declaring himself life-president in 1971. 


\section{Memory and the "Architecture of Hysteria"79}

In "Crocodile Lodge" Gordon Duffy is, in sharp contrast to the three other main characters of the narrative quartet that forms The Exploded View, a rather introverted, unassuming, and dour figure quietly going about the daily business of surviving the emerging post-apartheid city. It is almost as if he wishes to remain invisible, not by hiding in the crowd but by keeping away from the streets altogether. Middle-aged Gordon owns a small company that erects billboards, especially at the construction sites of new housing developments. Duffy's experience of the city is largely through his car, as he traverses the veld around the city in executing his work. His experience of the city is contrarian to Benjamin's notion of flâneurism as reflected in the modalities of postcolonial mobilities, movements, and car-driving in Johannesburg (Jones 389). This kind of mobility introduces sensations that are different from the street-level enunciations that are the hallmarks of the flâneur. His story is told to the accompaniment of the radio traffic news report that becomes something of a refrain or chorus that maps not only the congested nodes of the city's major arteries, but also assists individuals like Duffy in negotiating their way around the city, in the physical and metaphorical senses as discussed more fully in Susan van Zyl's "Skyhooks and Diagrams: The Signing of Ivan Vladislavić's The Exploded View” (75-84).

"The exploded view" of the title of the novel literally manifests itself in this section of the text (Vladislavic 189) and figuratively as a strategy of viewing and gaining insight into various objects by breaking them down into their constituent parts-a strategy that he adapts from the magazine Popular Mechanics during his childhood: "He closed his eyes and began to detach the components of the house one by one as if easing apart a delicate puzzle, finding the sketchy Braille of the plans on the tips of his fingers, reading the bones concealed beneath the coloured skin. He separated board from board, stone from stone" (189). There are echoes of Budlender engaging in a similar process of disassembling the security gate at Villa Toscana, but Duffy's method is much more sustained and exhaustive. At the heart of Duffy's process is the fact that he is struck by the way things perfectly fit together in Popular Mechanics. As a consequence, the US comes to stand, in his imagination, for a perfect entity. In this yearned-for world, everything has a place into which it seamlessly slots and life is thus safely predictable. This is in contrast to the jagged existence that is postcolonial Johannesburg, an existence that Duffy ultimately finds to be more threatening than colorful.

79 Originally used by Achille Mbembe (2004) and further enunciated as well as utilized in reference to Vladislavić's writing by Shane Graham (2006). 


\section{Correcting the Imperfect Past}

Having established that the strategy of disassembling things is a mechanism for coping with the pressures of the present by invoking a past of perfection and order, it is within this general rubric of depicting the postcolonial metropolis that the twin themes of remembering and the now are examined. Individual characters avail themselves differently of the processes and technologies of memory and remembering in order to articulate their particular understanding of the historical moment of the present, as well as to appropriate certain social and physical space in the emergent postcolonial city. In this connection, Duffy's enunciations of the latter evoke a poignancy that is not so pronounced in any of the other three principal characters in this text. This is because he makes no claim to any form of superior wisdom or talent in the manner displayed by the others, or even a character like Aubrey Tearle from Vladislavić's 2001 novel, The Restless Supermarket. In spite of his keen childhood interest in the field of mechanical engineering (as seen in his love for Popular Mechanics), he does not grow up to become an engineer but more of a semi-skilled handyman drifting from one job to the next, until (in his 30s) he decides to start his own businesses. For the most part, these ventures follow his own early, non-descript patterns in that they show a lack of focus and specialization in a particular skill-that is, until he starts erecting billboards. In his uncertainty with the now, he constantly looks back into his past in search of meanings. The postcolonial now is, for Duffy, a new discursive terrain, but the survival skills of the past, which he may not have even fully mastered, prove hopelessly inadequate for the present contingencies. The world of Popular Mechanics, with everything neatly assigned its place, can be read as a metaphor for the order of the apartheid city in which everyone knew their place, whereas post-apartheid Johannesburg is much more volatile and unpredictable than Duffy has the social and mental resources to successfully navigate.

Michael Titlestad and Mike Kissack, writing on the poetics of invention in The Exploded View, have rightly pointed to the "two structures of memory" that are discernible in the "Crocodile Lodge" narrative (17). These are, namely, "a recurrent boxing dream in which Duffy compensates for his childhood humiliation at the hands of Wilkie Pieterse by beating him senseless" and "the world of Popular Mechanics" (17). Titlestad and Kissack are generally correct in their conclusions as to how Duffy's memory is structured and operates. However, they make a potentially fatal misreading of the text of "Crocodile Lodge" in their assertion that Duffy is always beating his adversary in the recurrent dreams. This is because the plot alludes to the fact that in the dreams, it is Wilkie Pieterse who usually beats Duffy (as was the situation in "real" life when they met in a boxing match in their boyhood) and not the other way around. It is only in the last version of the dream that the latter emerges victorious. I would suggest that Titlestad and Kissack's following of the plot in this instance is flawed to the extent that they suggest that Duffy's dream "victories" are part of a strategy to compensate for his real-life humiliation. At issue is the interpretative dif- 
ference between dreams in which he emerges as winner and the dreams in which he is beaten, save for the one time. If, on the other hand, all the dreams had ended in a Gordon Duffy triumph, only then would it be justifiable for Titlestad and Kissack to see this as a compensatory gesture.

While the dreams are important to the structuring of memory, Titlestad and Kissack's analysis suffers from placing too much emphasis on the outcome, an outcome which-in my opinion-they have misread. The point of emphasis should rather be on the recurrence of the dream as a measure of how Duffy is preoccupied with a past he is now powerless to change. This fact is buttressed by the revelation by the character that "[t]his was his first victory" and "[i]t left him feeling strangely dissatisfied” (Vladislavić 168). Dreams in which he would have constantly conquered would have been the more appropriate gesture of compensation and his disgruntlement (as opposed to elation) with the single "victory" when it finally comes illustrates how, in my estimation, Duffy is not merely seeking to rid himself of a past humiliation. Rather, the recurrence of the dream points to a level of dissatisfaction with the present, the now of post-apartheid Johannesburg in which the humiliations of the past seemingly continue to manifest themselves and are replicated.

\section{Uncomfortable Truths, Unwanted Pasts}

In the "Aesthetics of Superfluity," 80 Achille Mbembe defines Johannesburg as "an African form of metropolitan modernity" (373), and further states that:

In the South African context, surfaces such as Montecasino and, to a lesser extent, Melrose Arch represent new genres of writing time. But this new inscription of time is paradoxical. For it to be possible at all, the built form has to be construed as an empty placeholder for meanings that have been eroded by time rather than remembered by it. That is why they are largely the manifestation of the failure of the racial city to assimilate the passage of time. While bearing witness to a demand that the past be forgotten, this architecture asks the spectator to forget that it is itself a sign of forgetting. But in so doing, it reiterates the pathological structure and hysteria inherited from the racial city. This is an architecture of hysteria. (402)

For Mbembe, places like Montecasino and Melrose Arch instantiate, in their reiteration of otherworldly architecture, the notion of wanting to forget the separations of the past. The paradox lies in the fact that while these forms of architecture are meant or designed to show that people can move on from the things which divided them in the past, the structures become self-evidently contradictory in the sense that in

80 First published in a special issue of Public Culture (Mbembe) and later as part of an expanded monograph, Johannesburg: The Elusive Metropolis (Nuttall and Mbembe), which is concerned with the difficulty of representing the city. Mbembe co-edits both of these volumes with Sarah Nuttall. 
their apartness from other areas of the city, they show that little or nothing has been learned from the history of the apartheid city. Put simply, the new edge cities represent a new form of economic apartheid as they are designed to be enclaves for an affluent class that figuratively exists in a different world from the poor majority.

With respect to Duffy and following on Mbembe's argument above, the recurrent dream represents the failure, at the personal level, "to assimilate the passage of time." The consequence of this failure is a form of hysterics that manifests and is performed at the personal level by Duffy. The dream represents an inability to constructively mark and integrate the passage of time. This is true, even if Mbembe's article is, to a greater extent, concerned with the physical architecture of the post-apartheid city, such as Montecasino and Melrose Arch, which, in their evocations of places "other" than or elsewhere to the specific African context in which they are located, represent "new ways of writing time." They speak to a cosmopolitan, postcolonial time but are held back by the material contradictions of the past. In the broader context of Vladislavićs writing, Mbembe’s analysis is also applicable to "Villa Toscana” in its rendering of a "Little Tuscany" on the veld of Johannesburg. Duffy's hysteria, as marked by his dream, takes the form of constant and nervous backward glances into the past in search of comfort and meanings that remain unattainable. To a large extent, Duffy is unable to fully inscribe himself into the present because his sojourns into the past (a past which in any event appears to some degree to have been possibly disenchanted) do not yield him the appropriate tools for doing so, that is, to assimilate himself fully into the present.

\section{Death of a Tomason}

The second "structure of memory" identified by Titlestad and Kissack is that of Popular Mechanics, a magazine popular with do-it-yourself boffins. The basic premise of the magazine is to instruct its readers about gadgets and technologies by offering pictorial perspectives in which these objects are broken down, or figuratively blown up, into their constituent parts-down to the last nut, bolt, and screw-and hence, the exploded view. This world which the young Duffy gets access to through his father's magazines is described by Titlestad and Kissack as a "nostalgic ideal" (17). Gerald Gaylard similarly defines Duffy as "a utopian functionalist who has to face his own fears in a forbidding new context” (67). The import of both descriptions is that Duffy, as an individual, retrospectively occupies this utopian world in which everything is in its place, and "[a]ll it needed was a touch, a prod with the tip of a finger, to shift everything closer together, and a perfect whole would be realized, superficially complete and indivisible” (Vladislavić 171). Duffy's problems partially lie in the fact that the order of this world, one in which "surfaces [are] airbrushed to perfection" and are "gleaming with old-fashioned optimism" (171), cannot be used to rationalize the 
"new disorders" of the (postmodern) post-apartheid city because the paradigms of the new reality are based on totally different premises from the old, for example, that of hybridity, whereas the older framework was one of rationalized separation. Tellingly, he is frustrated by the realization that the "surgical ability to see how things fitted together" (190) - a skill he had developed through reading Popular Mechanics - is an increasingly redundant talent in the contemporary world of the postcolonial metropolis: "But, in truth, this skill seemed to him increasingly outmoded in the world he lived in. It was no longer clear even to the most insightful observer how things were made or how they worked. The simplest devices were full of components no one could see, processes no one could fathom" (190). The new world lacks the predictability which he is used to, and thus he is unable to make sense of it. His missing cell phone, for instance, represents a whole that is less than the sum of its parts, as he considers all the possible fates that could have befallen it. This is so because it has functionality through unseen circuits, networks, and infrastructures that lie outside those represented by the interconnections in its physical parts. In the imagination, it connects him to all kinds of people and places that are beyond his normal, ordered trajectories. Duffy speculates about "his telephone voice, disembodied and businesslike, speaking out of some thief's pocket" or his "phone lying on a makeshift table in a shack, among four beer bottles and ashtrays" (180). The radio traffic reports that function like a refrain to constantly retrieve him from his reveries and the past, offer panoramic views of the city but also, in the almost perpetual gridlock that they relate, show how the city does not function in the orderly flows suggested by the Popular Mechanics diagrams.

Like a Tomason, Duffy is a puzzling relic from the past, and his failure to adapt to the new order instantiates how "the structures of apartheid persist because their well-established mentalities do" (Beilharz and Supski 11). In the end, four black men disembark from a minibus and approach with obvious menace as one of them is holding a length of piping. The four men he had imagined drinking in a shack around his stolen phone transform from dream to reality. Their calm approach to rob him transfixes him, and he is literally like a hare caught in the headlights of a car as he stands in the light cast by his own truck. I read this hare-in-the-headlights moment as a poignant metaphor for the imaginative paralysis that seems to afflict the majority of the white characters in the text. The beating, when it comes, restages the childhood humiliation at the hands of Wilkie Pieterse in Duffy's inability to defend himself or otherwise take any kind of evasive action. There is no chorus like that of the traffic report to forewarn him of the imminent danger, and the irony is that "with every blow he felt like himself" (Vladislavić 201). The paradox of this violence lies in the fact that it is only through this medium that Duffy gets a strange sense of affirmation in, and affinity to, the present, and he thus welcomes it. In a strange way, the beating becomes a catalyst for his recuperation. 


\section{Conclusion}

Vladislavić's The Exploded View explores the construction and spatialization of urban identities in the context of the South African transition to the post-apartheid state. By focusing on the last two sections of the novel, "Curiouser" and "Crocodile Lodge," I considered how the author utilizes the metaphor of the exploded view as a representational strategy in the process of problematizing the characters' and Johannesburg's idiosyncratic state of flux. This fluid state has at its core notions of hybridity and intersecting identities. Firstly, by doubling the metaphor of the "exploded view" on itself, this study examines how the self-defined cosmopolitan and avant-garde black artist Simeon Majara (in “Curiouser') re-presents, for instance, the Rwandan holocaust or re-shapes original pieces of art and curios to create new meanings. In his acts of resignification, Majara uncovers as much truth, if not more, about himself as a subject as about his art, about his city as a contradictory cosmopolitan space, as well as his and its place in the unevenly globalizing world. The second half of the chapter has brought into sharp focus the psycho-social trauma that accompanies the transition to a post-apartheid democratic polity for one white character, Gordon Duffy, in "Crocodile Lodge.” Duffy, as representative of type, displays nervous energy as he simultaneously glances backwards at apartheid (and its privileges for him as a white subject) and makes forays into a contradictory emergent social imaginary that is at once alive with old dangers and new possibilities. Taken together, both narrative strands have been used to highlight how transient identities evolve and dissolve on an urbanscape that is itself undergoing constant change in its physical infrastructure, as well as its socio-political and cultural dynamics.

\section{Acknowledgement}

The author acknowledges the assistance-through a research grant-of the National Research Foundation (South Africa) during the preparation of this chapter.

\section{Works Cited}

Beilharz, Peter, and Sian Supski. "Finding Ivan Vladislavić-Writing the City." Thesis Eleven, vol. 136, no. 1, 2016, pp. 5-19.

DeFazio, Kimberly. The City of the Senses: Urban Culture and Urban Space. Palgrave Macmillan, 2011.

Gaylard, Gerald. "The Death of the Subject? Subjectivity in Post-Apartheid Literature." scrutiny2: Issues in English Studies in Southern Africa, vol. 11, no. 2, 2006, pp. 62-79. 
Graham, Shane. "Layers of Permanence: Toward a Spatial-Materialist Reading of Ivan Vladislavic's The Exploded View." scrutiny2: Issues in English Studies in Southern Africa, vol. 11, no. 2, 2006, pp. 48-61.

Gray, Stephen. "Véronique Tadjo Speaks with Stephen Gray." Research in African Literatures, vol. 34, no. 3, 2003, pp. 142-147.

Jones, Megan. "Cars, Capital and Disorder in Ivan Vladislavic's The Exploded View and Portrait with Keys." Social Dynamics : A Journal of African Studies, vol. 37, no. 3, Apr. 2012, pp. 37-41.

de Kock, Leon. "So, What Should Academic Critics Be Doing, on the Edge of the Now-Skimming the Surface or Plumbing Those Depths?" English Studies in Africa, vol. 55, no. 2, 2012, pp. 3-17.

Marais, Sue. "The Economies of Repetition: The Market, the Artistic, and the Genocidal in Ivan Vladislavić's 'Curiouser.' " The Journal of Commonwealth Literature, vol. 52, no. 1, 2017, pp. 27-41.

Mbeki, Thabo. I Am an African. 1996, www.afrika.no/Detailed/18444.html. Accessed 2 Sep. 2010.

Mbembe, Achille. "Aesthetics of Superfluity." Public Culture, vol. 16, no. 3, 2004, pp. 373-405.

Mirzoeff, Nicholas. "Invisible Again: Rwanda and Representation after Genocide." African Arts, Trauma and Representation in Africa, vol. 38, no. 3, 2005, pp. 36-39.

Nuttall, Sarah. "City Forms and Writing the 'Now' in South Africa." Journal of Southern African Studies, vol. 30, no. 4, 2004, pp. 731-748.

Nuttall, Sarah, and Joseph-Achille Mbembe. Johannesburg: The Elusive Metropolis. Duke UP, 2008.

Tadjo, Véronique. The Shadow of Imana: Travels in the Heart of Rwanda. Heinemann, 2002.

Titlestad, Michael, and Mike Kissack. "Secular Improvisations: The Poetics of Invention in Ivan Vladislavic's The Exploded View." scrutiny2: Issues in English Studies in Southern Africa, vol. 11, no. 2, 2006, pp. 11-26.

Zyl, Susan van. "Skyhooks and Diagrams: The Signing of South Africa in Ivan Vladislavic's The Exploded View." scrutiny2: Issues in English Studies in Southern Africa, vol. 11, no. 2, 2006, pp. 75-84.

Vladislavić, Ivan. "Propaganda by Monuments." Propaganda by Monuments and Other Stories, David Phillip, 1996, pp. 13-38.

--.. The Exploded View. Random House, 2004.

---. The Restless Supermarket. David Philip, 2001. 
